\title{
Diagnóstico da caprinovinocultura no Cariri Ocidental da Paraíba (PB): estudo de caso de 2005 a 2015
}

A criação de caprinos e ovinos no semiárido brasileiro tem se consolidado nas últimas décadas como uma importante atividade de produção animal para a subsistência, servindo como meio para a fixação do homem ao campo. Neste sentido, tem-se a caprinovinocultura como uma alternativa de renda e alimentícia para muitas famílias que vivem no semiárido e que buscam sobreviverem diante das diferentes adversidades enfrentadas, como as condições ambientais, econômicas, entre outras. Partindo disso, o objetivo do estudo foi diagnosticar a distribuição quantitativa da caprinovinocultura na microrregião do cariri ocidental paraibano entre os anos de 2005, 2010 e 2015, a fim de entender a situação do efetivo de cabeças e o comportamento numérico dos rebanhos desses munícipios ao longo desses anos. Para isto, realizou-se uma pesquisa exploratória que pode ser caracterizada como um estudo de caso, sendo necessária a utilização da base de dados do censo agropecuário do IBGE (2017) para coleta e tabulação dos dados com o apoio do software Excel e logo depois plotado no software QGIS para facilitar a visualização espacial da quantidade de caprinos e ovinos em cada cidade contemplada na pesquisa. Como resultado, verifica-se que está havendo uma mudança na característica do rebanho do Cariri Ocidental da Paraíba (PB), onde apresentou uma redução do quantitativo de caprinos em 9\% e aumento da quantidade de ovinos em $31 \%$ ao longo desses 10 anos. Por fim, é fundamental entender a distribuição quantitativa da caprinovinocultura no intuito de fortalecer ainda mais esta importante cadeia produtiva através da criação e implementação de políticas pública para o setor e consecutivamente proporcionar uma melhor qualidade de vida para estes criadores.

Palavras-chave: Caprinovinocultura; Semiárido; Cariri Ocidental.

\section{Diagnosis of goat farming in Western Cariri da Paraíba (PB): case study from 2005 to 2015}

Goat and sheep rearing in the Brazilian semiarid region has been consolidated in recent decades as an important livestock production activity, serving as a means for the fixation of man to the field. In this sense, there is goat farming as an alternative for income and food for many families living in the semi-arid and seeking to survive in the face of different adversities faced, such as environmental, economic conditions, among others. Based on this, the objective of the study was to diagnose the quantitative distribution of goats in the Paraiba Western Cariri microregion between 2005, 2010 and 2015, in order to understand the head herd situation and the numerical behavior of these herds throughout of those years. For this, an exploratory research was carried out that can be characterized as a case study, requiring the use of the IBGE (2017) census database for data collection and tabulation with the support of Excel software and soon after. plotted in QGIS software to facilitate spatial visualization of the number of goats and sheep in each city contemplated in the research. As a result, it appears that there is a change in the characteristic of the West Cariri da Paraiba (PB) herd, which showed a reduction of goat quantity by $9 \%$ and an increase of sheep by $31 \%$ over these 10 years. Finally, it is essential to understand the quantitative distribution of goat farming in order to further strengthen this important production chain through the creation and implementation of public policies for the sector and consecutively provide a better quality of life for these breeders.

Keywords: Goat breeding; Semiarid; Western Cariri.

Topic: Desenvolvimento, Sustentabilidade e Meio Ambiente

Reviewed anonymously in the process of blind peer.
Received: 10/10/2018 Approved: 09/11/2018
Robson Fernandes Barbosa (10)

Universidade Federal de Campina Grande, Brasil

http://lattes.cnpq.br/5329317234568143

robson rfb@yahoo.com.br

Rafael Albuquerque Xavier (iD)

Universidade Federal de Campina Grande, Brasil

http://lattes.cnpq.br/3345367355585035

http://orcid.org/0000-0002-1737-7547

xavierra@uol.com.br

\section{Referencing this:}

BARBOSA, R. F.; XAVIER, R. A.. Diagnóstico da caprinovinocultura no Cariri Ocidental da Paraíba (PB): estudo de caso de 2005 a 2015. Revista Ibero-Americana de Ciências Ambientais, v.9, n.8, p.187-199, 2019. DOI: http://doi.org/10.6008/CBPC2179-6858.2018.008.0017 


\section{INTRODUÇÃO}

A criação de caprinos e ovinos tem uma importante contribuição para a atividade econômica da agricultura familiar de algumas regiões do Nordeste, e especificamente do semiárido brasileiro. Para Batista et al. (2015), a caprinovinocultura contribui para a fixação do homem ao campo e constitui-se numa atividade relevante, seja no contexto econômico, pela geração de fonte de renda para pequenos produtores, seja no contexto sociocultural, pela fixação do homem ao campo e perpetuação da atividade produtiva para as gerações seguintes.

Segundo os dados do IBGE (2016), houve um aumento na participação da Região Nordeste na criação de caprinos nos últimos dez anos, de 91\% no ano de 2007 para 93\% em 2016. A concentração do rebanho caprino na Região Nordeste está relacionada às questões culturais e de mercado, refletindo-se na organização da atividade, denotando um caráter predominantemente regional.

Em se tratando da participação da criação de ovinos, houve aumento da participação da Região Nordeste, a qual passou de 57\% em 2007 para 63\% em 2016. A ovinocultura apresenta diferentes aptidões produtivas conforme a região do país. Enquanto a produção nordestina é predominantemente voltada para a produção de carne, a produção sulista, com dupla aptidão, também inclui a produção de lã.

A criação de caprinos e ovinos representa considerada importância econômica para a população do cariri, servindo como uma poupança nos momentos de dificuldade financeira. Muitas vezes, os criadores comercializam sua criação para satisfazer necessidades emergenciais, tais como: pagamento de uma conta de energia ou compra do gás de cozinha, aquisição de medicamentos, entre outras necessidades básicas. Vale salientar que, além da caprinovinocultura proporcionar uma fonte de renda e de alimento para muitas famílias do semiárido paraibano, ela pode ser considerada uma alternativa de manter o homem no campo, evitando assim, o êxodo rural e seus impactos negativos, como por exemplo, vulnerabilidade social.

Assim, a pecuária, em função de sua maior capacidade de adaptação à seca, quando comparada às explorações agrícolas, representa uma das mais importantes atividades do agronegócio no semiárido brasileiro, e tem se constituído num dos principais fatores para a garantia da segurança alimentar das famílias rurais e geração de emprego e renda (LIMA, 2009).

Portanto, por mais que problemas recorrentes de estiagens causadas por chuvas irregulares e secas prolongadas nos últimos anos afetem a expansão da caprinovinocultura no Nordeste, não é suficiente para impedir o seu crescimento nos municípios da Paraíba, onde esta atividade produtiva está presente em todas as cidades do estado e mais fortemente na microrregião do cariri ocidental.

Assim, este estudo, objetivou realizar um diagnóstico a distribuição espacial da caprinovinocultura na microrregião do Cariri Ocidental paraibano entre os anos de 2005, 2010 e 2015, a fim de caracterizar a atividade nesses munícipios ao longo dos anos. Trata-se de uma pesquisa exploratória em que se utilizou dos Censos Agropecuários para quantificar espacialmente os rebanhos caprinos e ovinos nos vários munícipios analisados. 


\section{REVISÃO TEÓRICA}

\section{Caracterização do Semiárido}

O Semiárido brasileiro representa 11,39\% do território nacional e abriga $29 \%$ da população do país. Possui uma extensão de $969.589,4 \mathrm{~km}^{2}$, que corresponde a $62 \%$ do território nordestino (incluindo a parte Semiárida de Minas Gerais). A região semiárida compõe cerca de 74\% do Nordeste, sendo caracterizada pelas altas temperaturas, irregularidade pluviométrica e secas periódicas (CORREIA et al., 2011).

No tocante ao Semiárido do Cariri paraibano, tem-se uma área ocupada de $11.235 \mathrm{~km}^{2}$ distribuídos em trinta municípios, e apresenta a maior densidade de caprinos e ovinos do continente americano. O Cariri está inserido no Semiárido brasileiro, com clima quente e seco, temperatura média acima de $26^{\circ} \mathrm{C}$ à sombra e pluviosidade irregular entre os anos e entre os meses do ano, com valores variando de 250 até $700 \mathrm{~mm} /$ ano. Os solos são em geral, rasos, pedregosos e secos (GUIMARÃES FILHO et al., 2000). A vegetação natural predominante é a caatinga, rica em espécies forrageiras nos seus três estratos: herbáceo, arbustivo e arbóreo, com estudos revelando que acima de 70\% das espécies botânicas da caatinga participam significativamente da composição da dieta dos ruminantes (ARAÚJO FILHO et al., 2002).

Segundo informações contidas no Dossiê Nordeste Seco, o Semiárido brasileiro é a área semiárida mais povoada do mundo e, em função das adversidades climáticas, associadas a outros fatores históricos, geográficos e políticos, que remontam centenas de anos, abriga a parcela mais pobre da população brasileira, com ocorrência de graves problemas sociais.

Em consequência do comportamento das chuvas no Semiárido e da reduzida capacidade de retenção de água na maioria dos solos (JACOMINE, 1996), grande parte da população é altamente dependente da água de chuva, de sua captação e de seu armazenamento, uma vez que os rios apresentam regime temporário, com exceção do Rio São Francisco. O clima constitui a característica mais importante do Semiárido, principalmente devido à ocorrência das secas estacionais e periódicas (MENDES, 1997), que determina o sucesso da atividade agrícola e pecuária e a sobrevivência das famílias.

Um fator que interfere significativamente na produção de ruminantes no país é a questão da seca em algumas regiões, que se dá principalmente por causa da estacionalidade climática observada no Brasil, o que exige dos pecuaristas estratégias para reverter esse tipo de situação, muito frequente nas regiões semiáridas que se estende por determinadas regiões do país.

A exploração pecuária da Região Nordeste é prejudicada pelas constantes secas e irregularidade das chuvas, pois, as precipitações ficam ausentes por longos períodos do ano, causando assim, uma baixa produtividade de seu rebanho. Em casos extremos, muitos animais não resistem à seca, e acabam morrendo por falta de uma alimentação adequada, ou até mesmo pela escassez de água.

Em virtude da baixa produção de grãos na região Nordeste (FERREIRA et al., 2004) o uso de subprodutos da agroindústria constitui um importante alternativo para alimentação dos rebanhos em sistemas intensivos e semi-intensivos. Representando uma fonte alternativa de nutrientes, o uso de subprodutos industriais na alimentação animal também promove à redução da contaminação ambiental e 
barateia os custos de produção, devido ao seu preço ser, normalmente, inferior aos suplementos convencionais. Assim, a natureza semiárida impôs a esses animais condições limites de sobrevida: ou se adaptavam, ou morriam perdidos pelas Caatingas. Nesse processo de adaptação, o instinto de sobrevivência falou mais forte e as cabras e ovelhas diminuíram suas capacidades de produção de leite e carne, mas ganharam rusticidade - leia-se adaptabilidade às Caatingas.

\section{A caprinovinocultura do semiárido}

A caprinovinocultura no Nordeste brasileiro constitui- se numa atividade de extrema importância, seja no contexto econômico, pela geração de fonte de renda para pequenos produtores, seja no contexto sociocultural, pela fixação do homem ao campo e perpetuação da atividade produtiva para as gerações seguintes. De acordo com MORAES NETO et al. (2003), a caprinovinocultura representa uma boa alternativa de trabalho e renda, visto a produção de alimentos de alto valor biológico (leite, carne e vísceras), bem como de pele de excelente qualidade, além da adaptabilidade dos animais aos ecossistemas locais.

Como são animais rústicos, conseguem sobreviver a temperaturas adversas como é o clima semiárido do Cariri paraibano. Caracterizado, com clima quente e seco, temperatura média acima de $26^{\circ} \mathrm{C}$ à sombra e pluviosidade irregular entre os anos e entre os meses do ano, com valores variando de 250 até $700 \mathrm{~mm} / \mathrm{ano}$. Os solos são em geral, rasos, pedregosos e secos. A vegetação natural predominante é a caatinga, rica em espécies forrageiras nos seus três estratos, herbáceo, arbustivo e arbóreo, com estudos revelando que acima de $70 \%$ das espécies botânicas da caatinga participam significativamente da composição da dieta dos ruminantes (ARAÚJO FILHO et al., 2002).

A região semiárida compõe cerca de $74 \%$ do Nordeste, sendo caracterizada pelas altas temperaturas, irregularidade pluviométrica e secas periódicas (CORREIA et al., 2011). Aproximadamente 55\% do semiárido nordestino é recoberto por pastagens da caatinga, que se torna, nos períodos de estiagem, o recurso forrageiro de maior expressão, contendo grande variedade de plantas nativas com alto valor nutricional, inclusive proteico, capazes de suprir as necessidades nutricionais dos animais.

Verifica-se que, na região semiárida, a principal limitação dos rebanhos caprino e ovino, sobretudo nas épocas de seca é prover da sustentabilidade alimentar dos animais. Com a vegetação escassa e o alto custo para a suplementação tem como consequência última a redução dos rebanhos, seja pela venda de parte dos animais para manter o restante do rebanho ou ainda, de forma mais crítica, pela morte dos animais resultado da desnutrição prolongada. Obstante a esse fato, nota-se que a prática de conservação de forragem através da fenação ou silagem não está amplamente difundida sendo ainda pouco utilizada pelos produtores.

No semiárido, o sistema predominante de produção de ovinos e caprinos para corte é o extensivo, dependente da vegetação de caatinga e caracterizado pela utilização de animais com genótipos não especializados. Este sistema está quase sempre associado a cultivos de subsistência, com índices de desempenho baixos associados à alta mortalidade de animais e a idade tardia para atingir o peso de abate (GUIMARÃES FILHO et al., 2000). 
Apesar das altas taxas de crescimento dos rebanhos caprino e ovino, a exploração no semiárido do Nordeste ainda é conduzida de modo extensivo, ou seja, sem nenhum controle sobre os rebanhos. Na época chuvosa, a alimentação dos animais é proveniente exclusivamente da pastagem nativa (caatinga) e, em alguns casos, da pastagem melhorada pelo raleamento. Na época seca, além das pastagens nativas, os animais são colocados nas áreas de colheitas, para aproveitarem os restolhos de culturas. Em algumas propriedades, verifica-se o fornecimento de suplementação com grãos ou outro alimento.

O rebanho no semiárido paraibano geralmente é constituído de animais nativos, SRD (Sem Raça Definida) ou mestiços, estes últimos, decorrentes de cruzamentos desordenados entre animais exóticos e nativos ou da utilização de reprodutores mestiços com diferentes composições genéticas - "grau de sangue". O rebanho ovino é constituído, na sua maioria, por ovinos deslanados como o Santa Inês, Morada Nova, Somalis Brasileira, Cariri e seus mestiços. As principais raças nativas e/ou tipos caprinos do NE são a Moxotó, Canindé, Repartida, Marota, Cabra Azul etc.

Os rebanhos apresentam certo índice de consanguinidade devido ao fato de não haver renovação periódica dos reprodutores, levando ao aparecimento de criptorquidismo, prognatismo, agnatismo, além de nos caprinos, aparecerem, com certa frequência, reprodutores mochos, os quais provocam problemas na fertilidade do rebanho e, por conseguinte, reduzem a produtividade do rebanho. O setor apresenta um desequilíbrio entre a produção na propriedade, o abate formal de animais e o setor de curtimento das peles, tornando necessário o trabalho conjunto dos diversos elos da cadeia produtiva, de maneira a reduzir os custos operacionais e aumentar a lucratividade e a sustentabilidade do sistema (COUTO et al., 2000).

Em termos de qualidade da carne, estima-se, segundo Couto (2001), que mais de $90 \%$ do abate total é feito de forma clandestina; todos os abatedouros oficiais trabalham com grande capacidade ociosa. Diante deste quadro, falar em qualidades sensoriais como sabor, maciez e suculência ou de formas de valorização dos nossos produtos, como rendimento e valorização da carcaça por meio de cortes regionais, parece não ter muito sentido.

Assim, a caprinovinocultura do semiárido paraibano é uma importante atividade econômica e de forte identidade cultural para o povo dessa região. Contudo, deve ter uma maior preocupação de como acontece a exploração atividade agropecuária, considerando os fatores ambientais (uso da energia, conservação da biodiversidade, manejo do solo e da água, qualidade do ar, etc.), econômicos (políticas de trocas justas, acesso aos mercados, demanda pelos produtos, créditos, financiamentos, etc.), e sociais (fatores culturais, tradições, política, sociedade civil).

\section{METODOLOGIA}

\section{Caracterização da pesquisa}

Esta pesquisa é caracterizada como exploratória, pois segundo Gil (2007), este tipo de pesquisa tem como objetivo proporcionar maior familiaridade com o problema, com vistas a torná-lo mais explícito ou a 
construir hipóteses. Assim, através da coleta de dados secundários foi possível explorar o fenômeno da distribuição quantitativa de cabeças de caprinos e ovinos na microrregião do cariri ocidental.

Essa pesquisa pode ser classificada como pesquisa bibliográfica, na qual se pesquisou eixos temáticos sobre a caprinovinocultura no semiárido. E classificada também como um estudo de caso, em o pesquisador não pretende intervir sobre o objeto a ser estudado, mas revelá-lo tal como ele o percebe. 0 estudo de caso pode decorrer de acordo com uma perspectiva interpretativa (FONSECA, 2002).

\section{População e amostra}

A Microrregião do Cariri Ocidental e a Microrregião do Cariri Oriental fazem parte da Mesorregião da Borborema, em que contempla um total de 31 municípios. Delimita-se, enquanto espaço de desenvolvimento da pesquisa, o Cariri Ocidental paraibano por apresentar maior quantidade de municípios, totalizando 17 (Amparo, Assunção, Camalaú, Congo, Coxixola, Livramento, Monteiro, Ouro Velho, Parari, Prata, São João do Tigre, São José dos Cordeiros, São Sebastião do Umbuzeiro, Serra Branca, Sumé, Taperoá e Zabelê). Optou-se por esta microrregião ao invés do Cariri Oriental por apresentar a maior extensão territorial, pujança econômica e maior representatividade/quantidade de criadores e números de caprinos e ovinos.

\section{Caracterização do espaço da pesquisa}

O cariri ocidental possui uma população estimada em 2015 pelo IBGE em 127.274 habitantes e está dividida em dezessete municípios. Possui uma área total uma extensão territorial de $7.075,10 \mathrm{~km} 2$, a população que reside na zona rural corresponde a $37,42 \%$ do total. Na figura 1, pode-se observar a diferença do tamanho territorial e a quantidades de cidades presentes entre as microrregiões do Cariri Ocidental e Oriental do Estado da Paraíba.

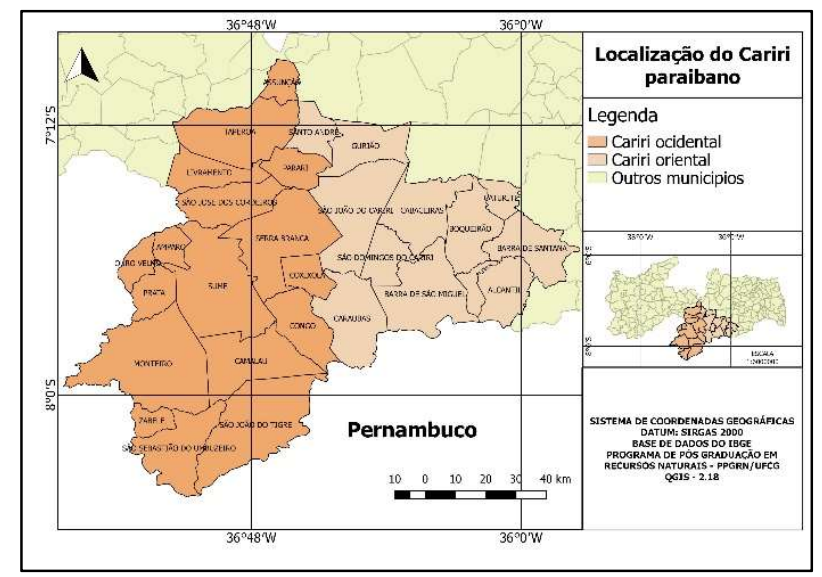

Figura 1: Localização do Cariri Ocidental.

\section{Etapas da pesquisa}

A pesquisa se dividiu de quatro etapas, além da pesquisa bibliográfica. A primeira etapa foi referente a obtenção dos dados acerca da quantificação de cabeças do rebanho 'ovino' e 'caprino' através da aba 'IBGE 
cidades' e logo após a aba 'Censo Agropecuário' no qual foi levantado os dados um a um dos 17 municípios referentes a microrregião do cariri ocidental paraibano e tabulados em uma planilha do software Excel. Na segunda etapa, foram baixados os shapes dos municípios paraibanos utilizados na elaboração dos mapas obtidos através do Geo portal da AESA.

Logo em seguida, na etapa terceira, os shapes foram abertos no software livre de elaboração de mapas, Quantum Gis (QGIS) versão 2.18 'Las Palmas de Gran Canárias'. A partir do auxílio da tabela de atributos em que os dados do IBGE (censo agropecuário) foram inseridos, fez-se necessário elaborar a estratificação dos mapas, em que preferiu dividir em 5 escalas quantitativas, mas não seguindo um padrão de intervalos entre as escalas geradas. Iniciando a partir do menor valor identificado entre os municípios, e a partir daí, criar intervalos com base no histograma, a fim de facilitar uma melhor visualização e distribuição das cores nos mapas. Por fim, na última etapa, geraram-se os mapas da distribuição quantitativa de caprinos e ovinos dos anos 2005, 2010 e 2015 e foram analisados seus comportamentos ao longo dos anos.

\section{RESULTADOS E DISCUSSÃO}

A partir dos dados analisados, pôde-se constatar que $88 \%$ do total de municípios predomina a criação de caprinos ao invés de ovinos. Apenas os municípios de Prata e Ouro Velho possuem maior quantidade de ovinos em relação a caprinos. Este fenômeno só foi observado a partir de 2015 (tomando como base os três anos analisados - 2005, 2010 e 2015), até então os referidos municípios apresentavam um comportamento como os demais municípios, ou seja, prevalência de caprinos em detrimento de ovinos.

O que se pode observar também é uma mudança gradativa da proporção entre o quantitativo de caprinos em comparação aos ovinos, pois em 2005 existia 128\% a mais do rebanho de caprinos em detrimento ao rebanho de ovinos, em 2010 essa discrepância caiu e apresentou 100\% de diferença, e por fim, em 2015 diminuiu ainda mais este percentual, com 60\% apenas de diferença, o que representa em termos absolutos 73.794 cabeças a mais de caprinos.

\begin{tabular}{|c|c|c|c|c|c|c|}
\hline \multirow[b]{2}{*}{ CIDADES } & \multicolumn{2}{|c|}{2005} & \multicolumn{2}{|c|}{2010} & \multicolumn{2}{|c|}{2015} \\
\hline & Caprino & Ovino & Caprino & Ovino & Caprino & Ovino \\
\hline Amparo & 10.000 & 5.500 & 8.000 & 4.800 & 4.880 & 3.968 \\
\hline Assunção & 2.323 & 206 & 2.184 & 608 & 3.273 & 1.842 \\
\hline Camalaú & 18.000 & 8.600 & 16.000 & 9.000 & 16.894 & 11.784 \\
\hline Congo & 8.500 & 5.200 & 8.500 & 5.800 & 8.007 & 7.184 \\
\hline Coxixola & 7.500 & 6.500 & 6.970 & 5.945 & 7.313 & 7.910 \\
\hline Livramento & 8.280 & 1.485 & 11.767 & 2.228 & 6.129 & 4.450 \\
\hline Monteiro & 32.000 & 12.000 & 28.240 & 12.500 & 29.584 & 18.332 \\
\hline Ouro Velho & 1.900 & 1.000 & 2.000 & 1.100 & 1.983 & 2.030 \\
\hline Parari & 8.500 & 2.100 & 8.100 & 2.400 & 8.617 & 2.629 \\
\hline Prata & 7.500 & 6.000 & 7.600 & 6.000 & 4.697 & 5.317 \\
\hline São João do Tigre & 16.200 & 4.200 & 16.870 & 5.000 & 20.122 & 6.030 \\
\hline São José dos Cordeiros & 5.000 & 2.300 & 6.000 & 2.800 & 8.936 & 3.500 \\
\hline São Sebastião do Umbuzeiro & 16.000 & 6.000 & 13.750 & 5.800 & 17.756 & 7.542 \\
\hline Serra Branca & 26.000 & 13.500 & 23.108 & 14.500 & 21.731 & 14.912 \\
\hline Sumé & 18.000 & 6.000 & 17.200 & 7.800 & 16.860 & 9.950 \\
\hline Taperoá & 18.591 & 8.806 & 15.244 & 10.001 & 11.009 & 10.841 \\
\hline Zabelê & 11.000 & 5.000 & 10.500 & 4.800 & 9.610 & 5.386 \\
\hline \multirow[t]{4}{*}{ Total } & 215.294 & 94.397 & 202.033 & 101.082 & 197.401 & 123.607 \\
\hline & & $r$ & & & & \\
\hline & $\begin{array}{l}128 \% \\
\text { de ca }\end{array}$ & $\begin{array}{l}\text { a mais } \\
\text { prinos }\end{array}$ & $\begin{array}{l}100 \% \\
\text { de ca }\end{array}$ & $\begin{array}{l}\text { a mais } \\
\text { prinos }\end{array}$ & $\begin{array}{l}60 \% \text { a } \\
\text { de cal }\end{array}$ & $\begin{array}{l}\text { a mais } \\
\text { prinos }\end{array}$ \\
\hline & $\begin{array}{l}\text { e caprinos } \\
2015\end{array}$ & & & $\begin{array}{l}\text { umento de } \\
5 \text { anos de } 2\end{array}$ & $\begin{array}{l}31 \% \text { de ox } \\
0005 \text { e } 2015\end{array}$ & $\begin{array}{l}\text { vinos entre } \\
5\end{array}$ \\
\hline
\end{tabular}


Nesse sentido, ao se analisar a caprinovinocultura destes municípios verifica-se uma redução da quantidade de caprinos, pois em 2005 totalizavam 215.294 cabeças e em 2015, um total 197.401. Ou seja, uma redução de $9 \%$, o que representa em números absolutos, 17.893 animais a menos. Já o comportamento quantitativo dos ovinos segue uma tendência contrária ao observado pelos caprinos. Em 2005 nos municípios pesquisados existiam 94.397 cabeças de ovinos e em 2015 aumentou e passou a ter 123.607, um acréscimo de 31\%. Diante os dados inicialmente apresentados, verifica-se no Quadro 01 o efetivo da caprinovinocultura por município ao longo dos 10 anos analisados.

Ao analisar os dados percebe-se que apenas quatro municípios paraibanos estão abaixo de $\mathbf{7 . 5 0 0}$ cabeças de caprinos, os municípios de Ouro Velho, Assunção, São José dos Cordeiros, Prata e Coxixola, respectivamente. Infere-se que uma das causas que pode justificar essa menor quantidade de animais esteja atrelado a menor dimensão territorial atribuída a estes municípios. Em contrapartida, os municípios de Monteiro, Serra Branca e Taperoá são os que apresentam respectivamente o maior quantitativo de cabeças de caprinos, conforme a figura 2 .

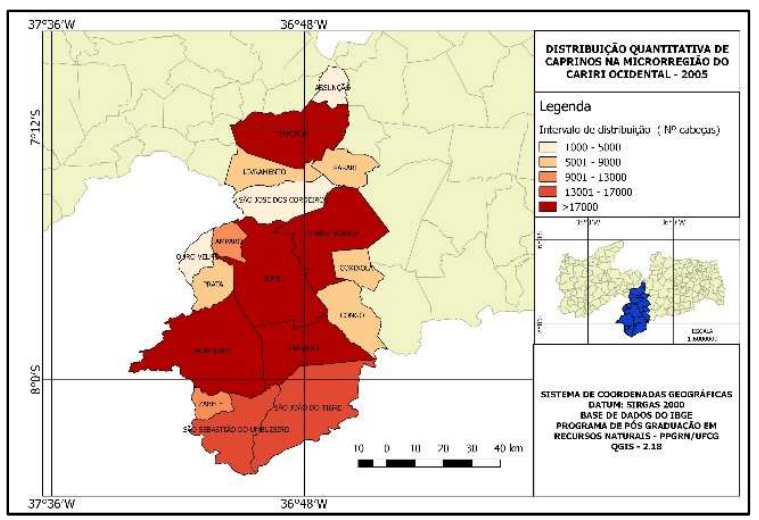

Figura 2: Mapa do quantitativo de caprinos 2005.

No tocante aos dados quantitativos de ovinos do ano de 2005, os municípios de Serra Branca, Monteiro e Taperoá, respectivamente, apresentavam 30\% do total de ovinos. Por outro lado, o município de Assunção só possuía 0,2\% de ovinos, o que corresponde em números absolutos a 206 cabeças. Desta forma, pode se considerar uma quantidade irrisória comparada aos outros municípios da região em relação a criação de ovinos, o que gera uma discrepância numérica e uma distribuição quantitativa oscilante, conforme se vê na figura 3.

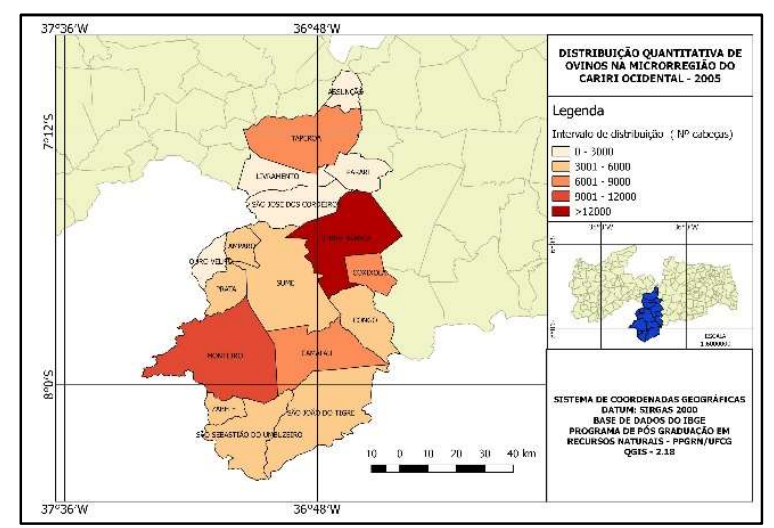

Figura 3: Mapa do quantitativo de ovinos 2005. 
$\mathrm{Na}$ figura 4, verifica-se a predominância do maior número de caprinos em relação a ovinos, em que todos os municípios seguem o mesmo comportamento ao se comparar a linha de tendência dos seus rebanhos na caprinovinocultura. É interessante observar que a cidade de Monteiro e Serra Branca disputam o ranking das maiores detentoras de rebanhos, enquanto Monteiro ocupava o primeiro lugar na criação de ovinos e Serra Branca, o segundo lugar, na criação de caprinos houve uma inversão de posições entra as duas cidades, tomando 2005 como ano base.

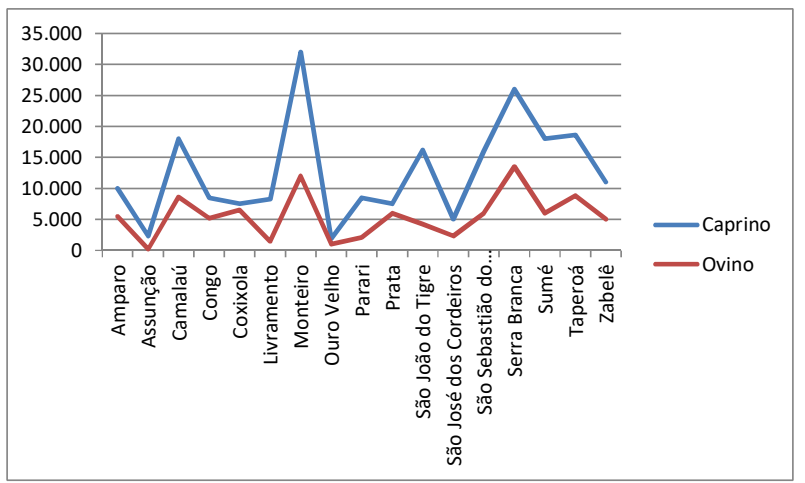

Figura 4: Distribuição quantitativa de caprinos e ovinos 2005.

Após obter o somatório de caprinos e ovinos no ano de 2005 de 309.691 cabeças, têm-se os municípios de Monteiro, Serra Branca, Taperoá, Camalaú e Sumé concentrando 52\% do total de rebanhos do cariri ocidental paraibano. Ou seja, apenas 30\% dos municípios concentram a metade de todo o rebanho da região. Cidades como Ouro Velho e Assunção concentram cada uma, apenas $1 \%$ do total de animais, conforme se ilustra na figura 5 .

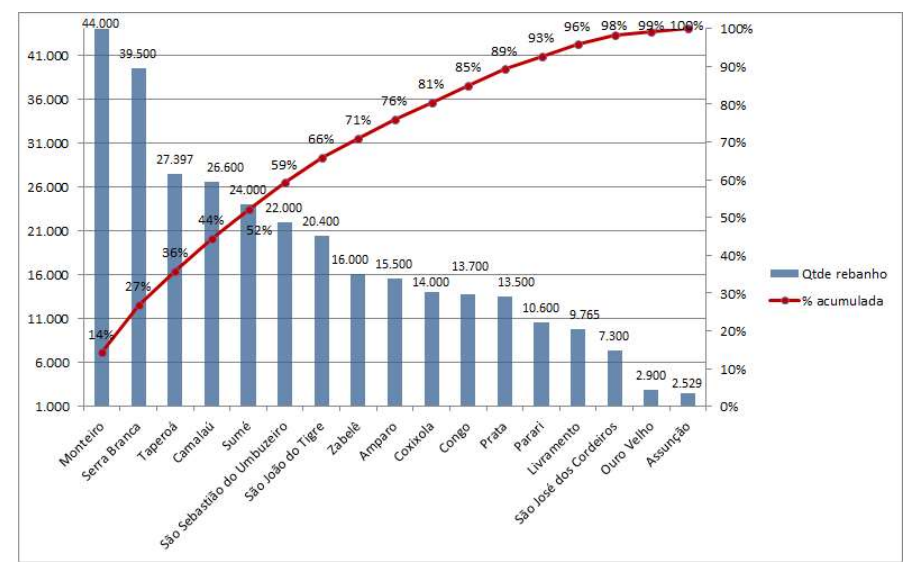

Figura 5: Distribuição acumulada da caprinovinocultura 2005.

Quando se compara a situação do quantitativo de caprinos de 2005 e 2010, verifica-se uma queda de 6\%, o que representa 13.261 cabeças a menos. Onde 17 (dezessete) municípios (Amparo, Assunção, Camalaú, Coxixola, Monteiro, Parari, São Sebastião de Umbuzeiro, Serra Branca, Sumé, Taperoá e Zabelê) tiveram decréscimos em seu rebanho de caprinos, 05 (cinco) municípios (Livramento, Ouro Velho, Prata, São João do Tigre, São José dos Cordeiros) apresentaram aumento do efetivo de caprinos e apenas a cidade do Congo não houve alteração na quantidade de caprinos entres os anos de 2005 e 2010, com 8.500 cabeças, conforme a figura 6 . 


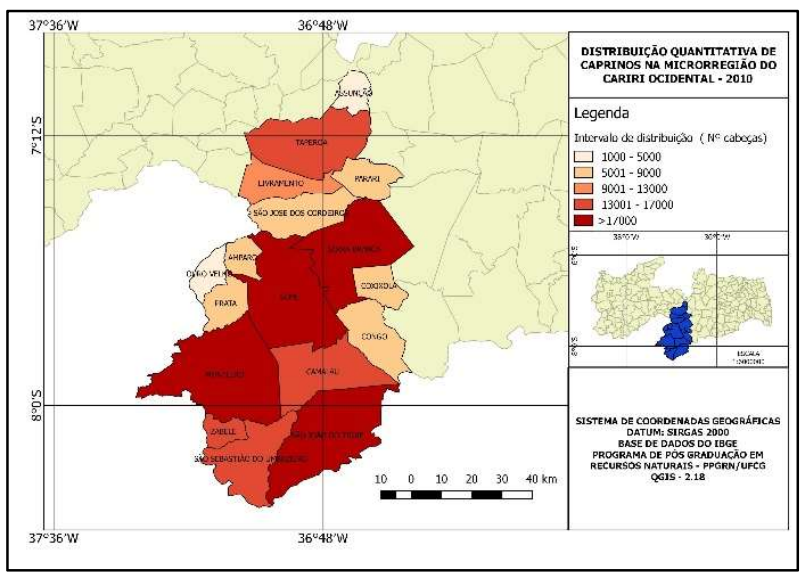

Figura 6: Mapa do quantitativo de caprinos 2010.

No tocante a distribuição quantitativa de ovinos no ano de 2010, verifica-se um comportamento contrário ao apresentado pelo mapa de caprinos do mesmo ano. Apenas 04 (quatro) cidades tiveram uma diminuição do seu rebanho, foram elas: Amparo, Coxixola, São Sebastião do Umbuzeiro e Zabelê. A cidade de Prata permaneceu a mesma quantidade e todos os demais municípios tiveram um aumento da quantidade de ovinos em relação a 2005. Em termos gerais houve um aumento de $7 \%$ do total de ovinos, o que representa 6.685 cabeças a mais (figura 7).

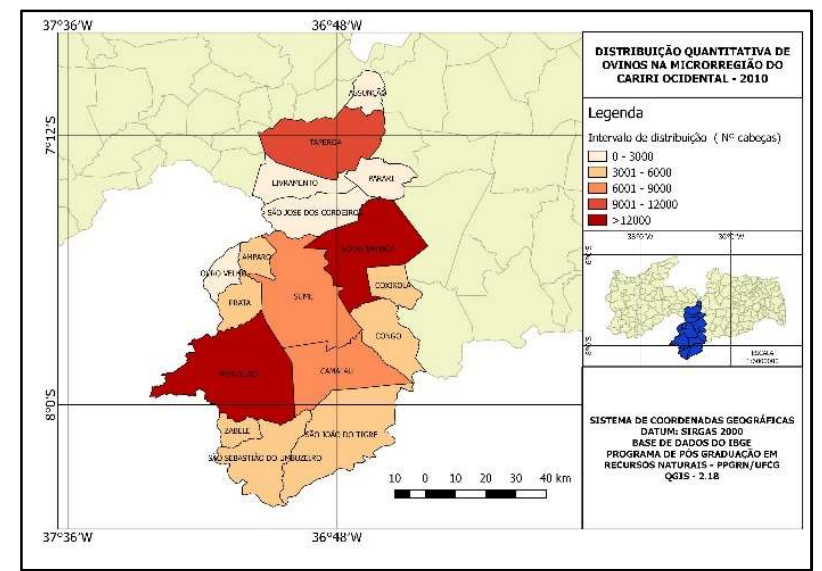

Figura 7: Mapa do quantitativo de ovinos 2010.

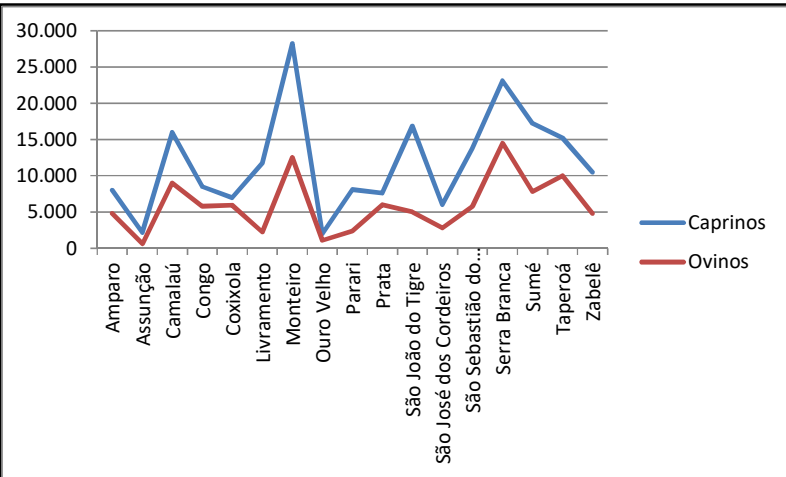

Figura 8: Distribuição quantitativa de caprinos e ovinos 2010.

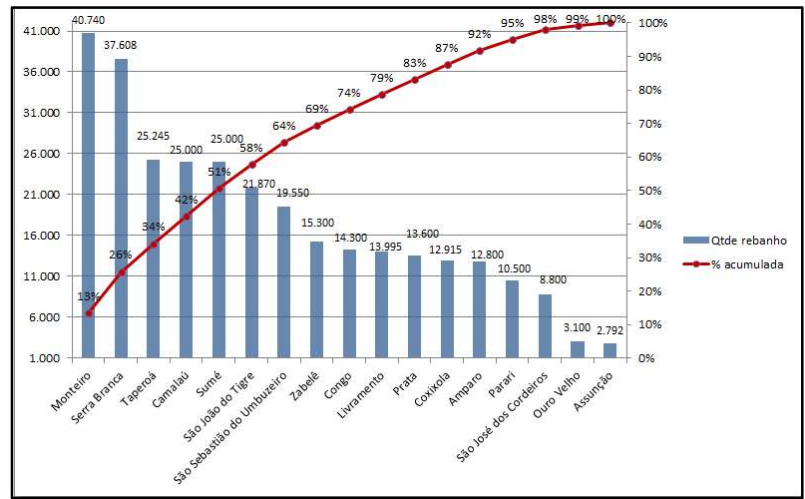

Figura 9: Distribuição acumulada da caprinovinocultura 2010.

Ao se analisar comparativamente o comportamento da distribuição quantitativa do ano de 2010, percebe-se pouca alteração em relação ao ano de 2005 , onde o comportamento tendencial é praticamente o mesmo, não havendo, assim, significativa mudança nas posições dos municípios. Observar-se-á isso na 
figura 8. O total de cabeças no ano de 2010 foi de 303.115, uma redução de 2,12\% em relação ao ano de 2005. As cidades Monteiro, Serra Branca, Taperoá, Camalaú e Sumé continuam concentrando metade do total dos rebanhos, com $51 \%$ do total. Não havendo um comportamento estatístico diferente do ano de 2005 , conforme a figura 9.

Não sendo diferente dos resultados anteriores, o ano de 2015 apresentou uma diminuição no rebanho de caprinos. Em comparação ao ano de 2010 houve uma diferença de $2 \%$ a menos e em relação a 2005 apresentou 8\% também a menos. A única cidade que teve um aumento considerado foi São João do Tigre, com um aumento de $16 \%$ a mais. Um dado curioso é o município de Livramento, onde teve o segundo maior aumento de caprinos de 2005 para 2010 com 3.487 cabeças e a maior diminuição de caprinos de 2010 para 2015 com 5.638 a menos, como se pode verificar através da figura 10.

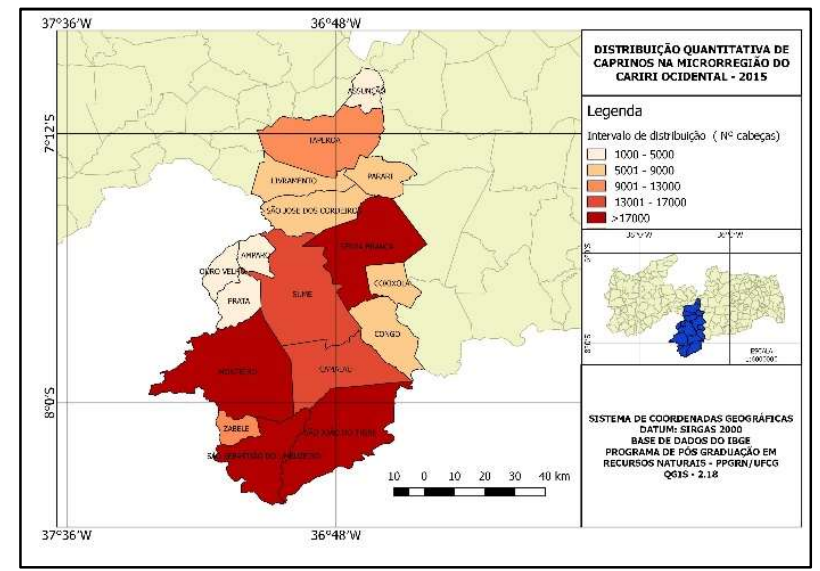

Figura 10: Mapa do quantitativo de caprinos 2015.

No que concerne à distribuição quantitativa de ovinos no ano de 2015, destacam-se 02 (duas) cidades, são elas: Ouro velho e Prata. Ambas foram as únicas cidades que a quantidade de ovinos ultrapassou a quantidade de caprinos. Vale ressaltar que em Ouro Velho praticamente tinha o dobro de caprinos em relação a ovinos em 2010 e que foi superado essa diferença em 2015. Em relação a cidade de Prata, justificase essa predominância dos ovinos não pelo seu aumento quantitativo, muito pelo contrário; houve uma diminuição de ovinos entre 2010 e 2015, mas maior ainda foi a diminuição de caprinos nos mesmos anos, como mostra a figura 11.

O ano de 2015 obteve um comportamento diferente dos anos de 2005 e 2010. Pois, até então, nenhuma cidade havia apresentado uma maior quantidade de ovinos em relação a caprinos; conforme citado anteriormente, apenas as cidades de Outo Velho e Prata. Isto demonstra que a caprinovinocultura do Cariri Ocidental paraibano vem passando por um processo de mudança e que as causas ainda precisam ser analisadas in locu nas propriedades dos criadores, conforme a figura 12.

O somatório dos rebanhos caprinos e ovinos no ano de 2015 foi de 321.008, o que representa um aumento 5,6\% a mais do quinquênio anterior. As cidades de Monteiro, Serra Branca, Camalaú, Sumé e São João do Tigre, lideram o quantitativo de animais com $52 \%$ do total. Os municípios de Camalaú e Sumé subiram uma posição cada, ocupando a 3 e 4o posição, respectivamente. A grande mudança foi a cidade de Taperoá, 
que ocupava a 3o colocação, e em 2005 e 2010, passou a ocupar a 7ํ posição, ficando atrás de São João do Tigre, e em seguida de São Sebastião do Umbuzeiro, sendo isso notável ilustrativamente pela figura 13.

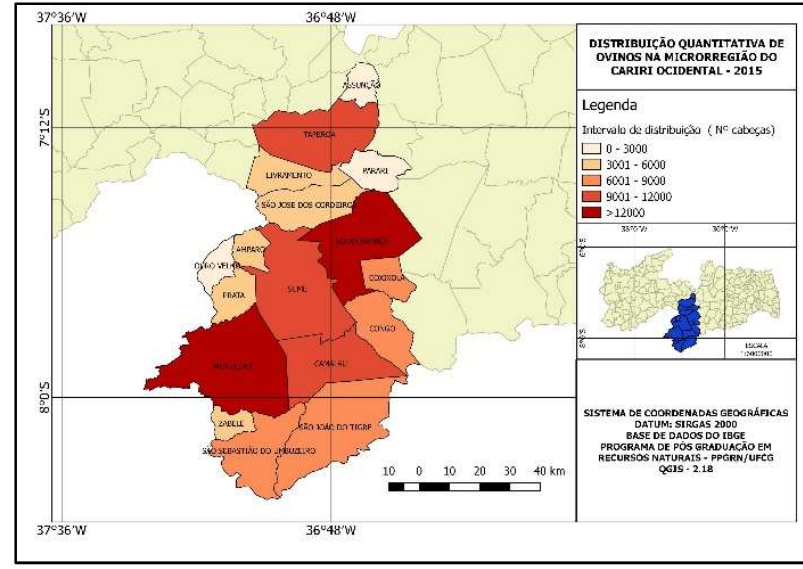

Figura 11: Mapa do quantitativo de ovinos 2015.

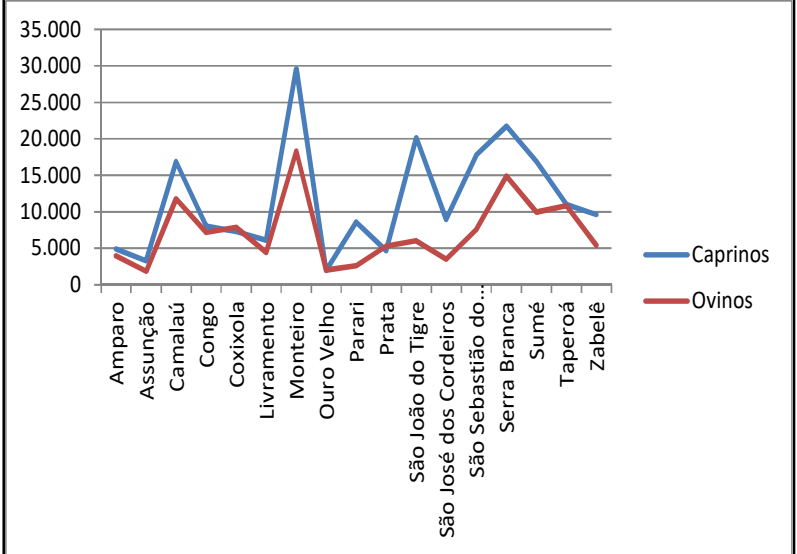

Figura 12: Distribuição quantitativa de caprinos e ovinos 2010.

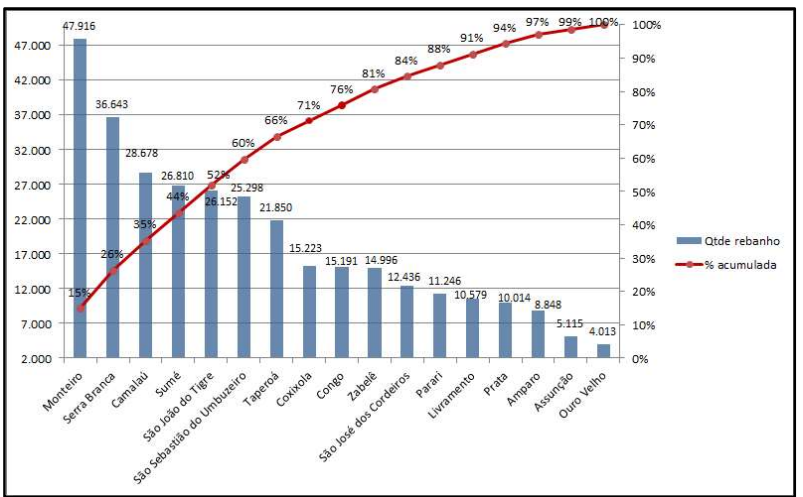

Figura 13: Distribuição acumulada da caprinovinocultura 2015.

Desse modo, ao se comparar a distribuição acumulada dos três anos (2005, 2010 e 2015), verifica-se que as cidades de Monteiro e Serra Branca sempre ocuparam respectivamente as primeiras posições da caprinovinocultura em termos quantitativos. A cidade de Taperoá foi a única do ranking das cinco primeiras que perdeu posição, dando vez a cidade de São José dos Tigres que passou a ocupar quinta colocação e Taperoá que em 2005 e 2010 ocupava a terceira colocação, passou para sexta posição.

\section{CONSIDERAÇÕES FINAIS}

Diante dos dados apresentados, verifica-se que houve uma redução na quantidade de caprinos e aumento na quantidade de ovinos ao longo das séries analisadas, o que denota certa preferência na criação de ovinos, tal fenômeno se justifique por questões de aceitabilidade do mercado ou pelo manejo menos trabalhoso, haja vista que é um animal menos andarilho e mais dócil, portanto, tem-se um menor risco de invadir propriedades vizinhas. Assim, o mapeamento realizado da caprinovinocultura do Cariri Ocidental paraibano pode apoiar a elaboração de políticas públicas a fim de fortalecer esta importante atividade produtiva para região. 


\section{REFERÊNCIAS}

ARAÚJO FILHO, J. A.; CARVALHO, F.C.; GARCIA, R.; SOUSA, R. A.. Efeitos da manipulação da vegetação lenhosa sobre a produção e compartimentalização da fitomassa pastável de uma caatinga sucessional. Revista Brasileira de Zootecnia, v.31, p.11-19, 2002.

BATISTA, N. L.; SOUZA, B. B.. Caprinovinocultura no semiárido brasileiro: fatores limitantes e ações de mitigação. Revista Agropecuária Científica no Semiárido, v.11, n.2, p.1-9, 2015.

CORREIA, R. C.; KIILL, L. H. P.; MOURA, M. S. B.; CUNHA, T. J. F.; JESUS JÚNIOR, L. A.; ARAÚJO, J. L. P.. A região semiárida brasileira. In: VOLTOLINI, T. V.. Produção de caprinos e ovinos no Semiárido. Petrolina: EMBRAPA, 2011. p.21-48.

COUTO, F. A. A.. Dimensionamento do mercado de carne ovina e caprina no Brasil. In: COUTO, F. A. A.. Apoio à cadeia produtiva da ovinocaprinocultura brasileira. Brasília: CNPq, 2001. p.10-15.

COUTO, F. A. A.; MEDEIROS, J. X.. Cadeia produtiva de caprinos e ovinos tropicais para carne, no Nordeste e Centro-Oeste do Brasil-Oportunidades e dificuldades. In: CONGRESSO BRASILEIRO DE REPRODUÇÃO ANIMAL, 14. Anais. Belo Horizonte: CBRA, 2000.

FERREIRA, A. C. H.; NEIVA, J. N. M.; RODRIGUEZ, N. M.; LOBO, R. N.; VASCONCELOS, V. R.. Valor nutritivo das silagens de capim-elefante com diferentes níveis de subprodutos da indústria do suco de caju. Revista Brasileira de Zootecnia, v.33, p.1380-1385, 2004.

FONSECA, J. J. S.. Metodologia da pesquisa científica. Fortaleza: UEC, 2002.

GIL, A. C.. Como elaborar projetos de pesquisa. 4 ed. São Paulo: Atlas, 2007.

GUIMARÃES FILHO, C.; SOARES, J. G. G.; ARAÚJO, G. G. L.. Sistemas de produção de carnes caprina e ovina no semiárido nordestino. In: SIMPÓSIO INTERNACIONAL SOBRE CAPRINOS E OVINOS DE CORTE. Anais. João Pessoa: EMEPA, 2000.

IBGE. Pesquisa Pecuária Municipal. Rio de Janeiro: IBGE, 2016.

JACOMINE, P. K. T.. Solos sob caatingas: Características e uso agrícola. In: ALVAREZ, V. H.; FONTES, L. E. F.; FONTE, M. P. F.. O solo nos grandes domínios morfoclimáticos do Brasil e o desenvolvimento sustentado. Viçosa: UFV, 1996. p.95-111.

MORAES NETO, O. T.; RODRIGUES, A.; ALBUQUERQUE, A. C. A.; MAYER, S.. Manual de capacitação de agentes de desenvolvimento rural (ADRs) para a Caprinovinocultura. João Pessoa: SEBRAE, 2003.

A CBPC - Companhia Brasileira de Produção Científica (CNPJ: 11.221.422/0001-03) detém os direitos materiais desta publicação. Os direitos referem-se à publicação do trabalho em qualquer parte do mundo, incluindo os direitos às renovações, expansões e disseminações da contribuição, bem como outros direitos subsidiários. Todos os trabalhos publicados eletronicamente poderão posteriormente ser publicados em coletâneas impressas sob coordenação da Sustenere Publishing, da Companhia Brasileira de Produção Científica e seus parceiros autorizados. Os (as) autores (as) preservam os direitos autorais, mas não têm permissão para a publicação da contribuição em outro meio, impresso ou digital, em português ou em tradução. 